\title{
Lower Extremity Kinetics in High and Low-Arched Athletes during Landing
}

Elizabeth T. Chalambaga ${ }^{1}$, Douglas Powell ${ }^{1}$, Doug Renshaw ${ }^{1}$, Matthew Bice ${ }^{1}$, Benjamin Long ${ }^{2}$

${ }^{1}$ University of Texas of the Permian Basin, ${ }^{2}$ East Carolina University

Int J Exerc Sci 2(1): S10, 2009. Abnormal foot function has been associated with an increased rate of injury in the athletic population. It has been shown that high-arched (HA) and low-arched (LA) athletes experience different injury patterns. These may be the manifestation of different loading and joint torque patterns in HA and LA athletes. It has been shown that HA and LA athletes have unique kinematic and kinetic patterns during running. However, little research has examined ground reaction forces (GRF) and lower extremity joint kinetics in HA and LA athletes during landing tasks. PURPOSE: To examine GRF and knee and ankle joint torques in HA and LA athletes during a landing task. METHODS: Ten HA (age: $20.8 \pm 2.5$ years; height: $1.62 \pm 0.07 \mathrm{~m}$; mass: $58.3 \pm 5.4 \mathrm{~kg}$; arch index: $0.386 \pm 0.010$ ) and 10 LA (age: $21.1 \pm 2.3$; height: $1.63 \pm 0.07 \mathrm{~m}$; mass: $58.9 \pm 10.9 \mathrm{~kg}$; arch index: $0.259 \pm 0.043$ ) female recreational athletes participated in this study. Each subject performed five barefooted drop landing trials from a height of $30 \mathrm{~cm}$. GRFs and three-dimensional (3D) kinematics were recorded simultaneously using a force plate $(1200 \mathrm{~Hz}, \mathrm{AMTI})$ and 7-camera motion analysis system $(240 \mathrm{~Hz}$, Vicon). GRFs and joint torques were calculated using Visual 3D (C-Motion, Inc.) and critical events were determined using custom software. A one-way ANOVA was used to compare group differences with an alpha level of $p<0.05$. RESULTS: The GRF profiles were similar between the HA and LA athletes. However, HA athletes exhibited a mean eversion moment compared to an inversion moment in LA athletes (HA: $0.05 \pm 0.08 \mathrm{Nm} / \mathrm{kg}$; LA: $0.04 \pm 0.07 \mathrm{Nm} / \mathrm{kg}$ ). Additionally, the HA athletes generated greater peak knee external rotation torques (HA: $0.18 \pm 0.06 \mathrm{Nm} / \mathrm{kg}$; LA: $0.26 \pm 0.08$ $\mathrm{Nm} / \mathrm{kg}$ ) compared to LA athletes during the landing task. Knee extension and abduction torques were similar between the two groups in contrast to previous findings. CONCLUSIONS: The greater mean eversion torques exhibited by the HA athletes may be a response to being more inverted throughout the landing task. Increased eccentric contraction of the ankle everters would control eversion during landing. Similarly, the increased knee external rotation torques would act to limit knee internal rotation during landing. These altered kinetic patterns may increase the risk of injury within these groups of athletes.

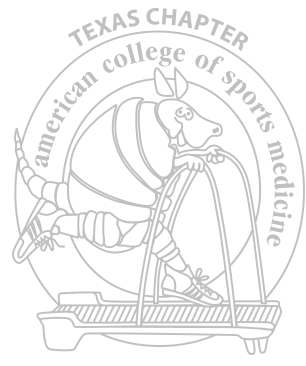

S10 